\title{
PENINGKATAN HASIL BELAJAR TEKNIK DASAR SEPAK BOLA DENGAN PENDEKATAN BERMAIN ANAK KELAS IX MTs NEGERI BATANG
}

\author{
WIJI SUTARSIH \\ MTs Negeri Batang \\ e-mail: sutarsih111@gmail.com
}

\begin{abstract}
ABSTRAK
Peningkatan Hasil Belajar Teknik Dasar Sepak Bola dengan Pendekatan Bermain Anak Kelas IX MTs Negeri Batang".Pada mata pelajaran Pendidikan Jasmani dan Olahraga Kesehatan (penjasorkes), terutama pada kompetensi dasar keterampilan teknik dasar sepakbola, banyak anak yang mengalami kesulitan sehingga mendapatkan nilai yang belum tuntas. Dari 29 anak kelas IX G MTs Negeri Batang, hanya 10 anak yang mendapatkan nilai tuntas. Padahal peneliti mengharapkan ketuntasan belajar anak pada mata pelajaran Penjasorkes tersebut mencapai $75 \%$ dari seluruh anak. Tetapi, hanya 34\% yang sudah mencapai batas dengan KKM 75 dengan rata - rata kelas sebesar 71.19. Penelitian ini mengkaji peningkatan hasil belajar anak dalam materi dasar teknik sepak bola dengan pendekatan bermain pada anak kelas IX G. Tujuan penelitian ini adalah untuk meningkatkan hasil belajar anak kelas IX G pada mata pelajaran penjasorkes kompetensi dasar keterampilan teknik dasar sepakbola dengan menggunakan pendekatan bermain. Penelitian ini berjenis kualitatif deskriptif. Sumber data dalam penelitian ini adalah anak kelas IX G MTs Negeri Batang. Berdasarkan hasil analisis data dapat disimpulkan bahwa penggunaan metode Tindakan Kelas (Action Research) sebagai upaya meningkatkan keterampilan teknik dasar sepak bola terbukti dapat meningkatkan hasil belajar dan latihan anak dengan persentase $34 \%$ menjadi $83 \%$.
\end{abstract}

Kata kunci : Penjasorkes, Sepak bola, Metode Tindakan Kelas (Action Research), Pembelajaran Penjasorkes, Hasil belajar anak.

\section{ABSTRACT}

Improving Learning Outcomes of Basic Football Techniques with Children's Playing Approach Class IX MTs Negeri Batang. . Of the 29 children in grade IX G MTs Negeri Batang, only 10 students got a complete score. In fact, the researchers expect the completeness of children's learning in Physical and Health subjects to reach $75 \%$ of all children. However, only $34 \%$ have reached the limit with a KKM of 75 with a class average of 71.19 . This study examines the improvement of children's learning outcomes in the basic material of soccer technique with a play approach in class IX G children. The purpose of this study is to improve the learning outcomes of children in class IX G in physical education subjects, basic competence in basic football technical skills using a play approach. This research is a descriptive qualitative type. Sources of data in this study were grade IX G MTs Negeri Batang. Based on the results of data analysis, it can be concluded that the use of the Action Research method as an effort to improve basic soccer technical skills has been proven to improve children's learning and training outcomes with a percentage of $34 \%$ to $83 \%$.

Keywords: Physical Education, Soccer, Action Research Method, Physical Education Learning, Children's learning outcomes.

\section{PENDAHULUAN}

Permainan sepak bola merupakan salah satu cabang olahraga yang sangat populer dan digemari oleh sebagian besar lapisan masyarakat. Olahraga ini semakin diminati oleh banyak orang karena dapat dinikmati dan dimainkan mulai dari anak-anak hingga orang dewasa. Daya tarik permainan sepak bola terletak pada kealamian permainannya (Rohim, 2008: 1). Berbagai alasan dan tujuan orang yang menggeluti olahraga ini antara lain sebagai olahraga rekreasi, mendapatkan kesehatan dan meningkatkan kebugaran jasmani, serta bertujuan untuk mencapai prestasi. 
Salah satu faktor yang mempengaruhi pencapaian sepakbola adalah kemampuan teknik dasar para pemainnya. Oleh karena itu, seorang pemain sepakbola yang tidak memiliki kemampuan teknik dasar sepakbola yang baik tidak mungkin akan menjadi pemain yang baik dan sulit mencapai hasil yang maksimal.

Program latihan keterampilan teknik dasar dilakukan secara teratur dan sebaiknya dimulai sejak usia dini. Untuk meningkatkan keterampilan teknik dasar sepakbola, biasanya akan dilakukan drill mengenai menendang (kicking), mengontrol/menghentikan bola (controling), menggiring bola (dribbling), menyundul bola (heading), melempar bola (trhowin) dan sebagainya. Aspek tersebut bertujuan untuk mengetahui dan meningkatkan keterampilan teknik dasar setiap pemain, karena tanpa keterampilan teknik dasar bermain sepakbola yang baik maka seorang pemain tidak akan dapat mengembangkan permainannya.

Agar teknik dasar sepakbola dapat dikuasai oleh anak, perlu latihan yang sungguhsungguh dan direncanakan dengan baik. Untuk mencapai hasil yang diharapkan pun perlu dukungan sarana prasarana yang memadai. Namun, pada kenyataannya tidak semua sekolah atau madrasah memiliki sarana dan prasarana yang memadai yang sesuai dengan harapan. Hal tersebut tentu menghambat anak untuk mampu menguasai teknik dasar permainan sepakbola yang menjadi salah satu kompetensi dasar pada mata pelajaran penjasorkes kelas IX, sehingga berpengaruh pula pada pencapaian Kriteria Ketuntasan Minimal (KKM).

Pencapaian KKM yang kurang maksimal terlihat pada hasil belajar anak kelas IX G dalam mata pelajaran penjasorkes, terutama pada kompetensi teknik dasar sepakbola. Dari 29 anak kelas IX G MTs Negeri Batang, hanya 10 anak yang mendapatkan predikat tuntas dalam materi teknik dasar sepakbola, dengan persentase ketuntasan sebesar 34\%. Hal tersebut masih jauh dari harapan peneliti yang mengharapkan ketuntasan mencapai $75 \%$.

Berangkat dari permasalahan tersebut, peneliti mencoba menerapkan salah satu pendekatan yaitu pendekatan bermain untuk meningkatkan hasil belajar anak. Wahjoedi dalam (Hasanuddin \& Hasanuddin, 2020 : 8) menuturkan bahwa pendekatan bermain adalah pembelajaran yang diberikan dalam bentuk atau situasi permainan. Dalam pendekatan ini, anak diberikan kebebasan untuk mengekspresikan kemampuannya terhadap tujuan pembelajaran yang telah diterapkan. Dengan cara tersebut, anak dapat mengembangkan kreativitas dan inisiatifnya untuk memecahkan masalah yang muncul selama proses pembelajaran berlangsung. Dalam pendekatan tersebut, anak juga dapat saling bersaing sehingga memunculkan unsur kompetitif antar anak. Pendekatan bermain dianggap sebagai sarana yang efektif dan efisien untuk meningkatkan kemampuan teknik dasar anak kelas IX G MTs Negeri Batang dalam pembelajaran permainan sepak bola.

Berdasarkan latar belakang di atas, peneliti merumuskan masalah sebagai berikut::

1. Apakah Penggunaan Metode Pendekatan Bermain dapat meningkatkan kemampuan tehnik dasar Anak kelas IX MTs Negeri Batang dalam permainan sepak bola.

2. Apakah Intensitas Latihan dengan metode Bermain dapat meningkatkan kemampuan tehnik dasar Anak kelas IX MTs Negeri Batang dalam permainan sepak bola.

\section{METODE PENELITIAN}

Penelitian ini dilakukan dengan menggunakan tindakan yang di dalamnya terdapat empat tahap kegiatan yaitu : perencanaan, pelaksanaan tindakan, observasi dan refleksi (Lewis dalam Rochiati, 2006) : keempat fase dari siklus PTK ini adalah : perencanaan, observasi, refleksi tindakan, dan evaluasi.

Dalam tahap perencanaan, peneliti menyusun dan memahami rencana penelitian dengan baik, yang dilanjutkan dengan tahap pengamatan terhadap proses atau hasil pembelajaran sepak bola si kelas IX G. Subjek pada penelitian kali ini adalah anak kelas IX G. Prosedur pengamatan dilakukan untuk mendapatkan data penelitian yang sesuai. Setelah mendapatkan data, peneliti melakukan tindakan refleksi, yakni tahapan mengkaji, melihat, dan mempertimbangkan hasil atau dampak dari tindakan dengan menggunakan berbagai kriteria. Berdasarkan hasil refleksi ini peneliti bersama-bersama rekan guru dapat merevisi untuk memperbaiki Penelitian 
Tindakan Kelas (PTK). Tahap terakhir yang dilakukan adalah evaluasi, yakni anak diberi evaluasi dalam peningkatan teknik dasar sepak bola (pasing/mengoper, menghentikan/ mengontrol, menggiring, menendang, menyundul, merebut bola)

\section{HASIL DAN PEMBAHASAN}

Hasil

Penelitian Tindakan Kelas ini dilakukan di MTs Negeri Batang yang terletak di Kabupaten Batang Provinsi Jawa Tengah. Letak dan suasana MTs cukup strategis dan cukup kondusif untuk melakukan proses belajar mengajar. Dari segi fisik, bangunan MTs ini cukup baik, walaupun ada beberapa gedung atau ruangan yang belum tersedia. Seperti Ruang Serbaguna atau GOR (Gedung Olah Raga). Sarana dan prasarana yang dapat mendukung kegiatan olahraga yang tersedia di MTs Negeri Batang ini tergolong lengkap, khususnya untuk sarana sepak bola yaitu : 1 lapangan sepak bola, 2 buah jaring gawang, dan 6 buah bola sepak.

Proses penelitian ini melibatkan anak kelas IX G MTs Negeri Batang yang terdiri berjumlah 29 anak, dari 17 anak putra dan 12 anak putri. Penelitian ini dilaksanakan satu minggu satu kali pertemuan. Siklus pertama dilaksanakan sebanyak 3 kali pertemuan dan direncanakan pada tanggal 17 Januari 2022 dimulai dengan pra siklus. Lokasi penelitian yaitu lapangan sepak bola MTs Negeri Batang dan dilaksanakan pada jam mata pelajaran penjasorkes.

1. Prosedur Dan Penelitian

Pada bagian ini setelah dilakukan rangkaian proses penelitian, selanjutnya peneliti akan menyajikan hasil penelitian antara lain : 1) Berkaitan dengan proses penelitian dalam bentuk siklus-siklus penelitian, 2) Menyajikan diskripsi data-data hasil penelitian.

2. Proses Dan Temuan Dalam Siklus-Siklus Penelitian

a. Pra Siklus

Sebelum dilakukan tindakan kelas, peneliti terlebih dahulu melakukan tes awal. Tes awal ini di lakukan untuk mengetahui sejauh mana tingkat keberhasilan anak dalam melakukan teknik dasar sepak bola sebelum dilakukan pembelajaran menggunakan latihan dasar sepak bola. Dari tes awal yang telah dilakukan menunjukan anak belum menguasai keterampilan ini. Di mana nilai rata-rata keterampilan passing dalam permainan sepak bola yang diperoleh pada saat tes 69,06. Berdasarkan pengamatan dalam pengambilan data awal tersebut menunjukan bahwa keterampilan awal anak perlu mendapatkan bimbingan yang efektif dalam mencapai hasil belajar yang diingikan. Hal-hal menyebabkan rendahnya tingkat keberhasilan tersebut di antaranya adalah penguasaan teknik dasar sepak bola yang masih kurang dan juga disebabkan cenderungnya guru hanya memberikan penjelasan secara teori dibandingkan dengan praktek atau demontrasi secara langsung terhadap materi yang akan diberikan, dan anak kurang termotivasi dengan metode pembelajaran yang diberikan. Untuk itu peneliti merasa perlu suatu tindakan perbaikan pembelajaran menggunakan latihan dasar sepak bola dengan pendekatan bermain, yang di sajikan secara sistematis dalam siklus tertentu.

Tabel 1. Penilaian passing dalam permainan sepak bola untuk putri Penilaian Passing Putri (1 Menit)

\begin{tabular}{|c|c|c|}
\hline NO & BANYAK PASSING & NILAI \\
\hline 1 & $10-15$ & 65 \\
\hline 2 & $16-25$ & 70 \\
\hline
\end{tabular}


Vol 2. No 1. Januari 2022 P-ISSN : 2774-8022, e-ISSN : 2774-5791

\begin{tabular}{|c|c|c|}
\hline 3 & $26-35$ & 75 \\
\hline 4 & $36-45$ & 80 \\
\hline 5 & $46-55$ & 85 \\
\hline 6 & $56-65$ & 90 \\
\hline
\end{tabular}

Tabel 2. penilaian passing dalam permainan sepak bola untuk putra Penilaian passing putra ( 1 menit)

\begin{tabular}{|c|c|c|}
\hline NO & BANYAK PASSING & NILAI \\
\hline 1 & $10-15$ & 60 \\
\hline 2 & $16-25$ & 65 \\
\hline 3 & $26-35$ & 70 \\
\hline 4 & $36-45$ & 75 \\
\hline 5 & $46-55$ & 80 \\
\hline 6 & $56-65$ & 90 \\
\hline 7 & $66-75$ & \\
\hline
\end{tabular}

Tabel 3. Tabel prasiklus

\begin{tabular}{|c|l|c|c|}
\hline No & \multicolumn{1}{|c|}{ Indikator } & Jumlah & Keterangan \\
\hline $\mathbf{1}$ & Jumlah Anak & 29 & \\
\hline $\mathbf{2}$ & KKM & 75 \\
\hline $\mathbf{3}$ & Indikator Keberhasilan & $34 \%$ \\
\hline $\mathbf{4}$ & Jumlah Anak Tuntas & 10 \\
\hline $\mathbf{5}$ & Jumlah Anak Tidak Tuntas & 19 & \\
\hline $\mathbf{6}$ & & & \\
\hline $\mathbf{7}$ & Jumlah Nilai & 2003 \\
\hline $\mathbf{8}$ & Nilai Rata-rata Kelas & 69,06 \\
\hline
\end{tabular}

Tabel 4. Tabel penilaian prasiklus

\begin{tabular}{|c|c|l|c|c|c|c|c|}
\hline \multirow{2}{*}{ NO } & \multirow{2}{*}{$\begin{array}{c}\text { NOMOR } \\
\text { INDUK }\end{array}$} & NAMA & \multirow{2}{*}{$\begin{array}{c}\mid \\
\text { L / }\end{array}$} & \multicolumn{3}{|c|}{ NILAI } & RATA \\
\cline { 5 - 6 } & & & P & I & II & III & RATA \\
\hline 1 & 6987 & Ahmad Nurwahid & L & 60 & 60 & 60 & 60 \\
\hline 2 & 6991 & Aidik Hadist Nur Syaputra & L & 75 & 75 & 80 & 77 \\
\hline
\end{tabular}


SECONDARY : Jurnal Inovasi Pendidikan Menengah Vol 2. No 1. Januari 2022 P-ISSN : 2774-8022, e-ISSN : 2774-5791

\begin{tabular}{|c|c|c|c|c|c|c|c|}
\hline 3 & 6990 & Alifatuddiniyah & $\mathrm{P}$ & 70 & 70 & 70 & 70 \\
\hline 4 & 7003 & Ana Ismatul Hawa & $\mathrm{P}$ & 60 & 60 & 65 & 62 \\
\hline 5 & 7011 & Ani Listiah Wati & $\mathrm{P}$ & 70 & 70 & 70 & 70 \\
\hline 6 & 7013 & Danar Dwi Anugrah & $\mathrm{L}$ & 60 & 60 & 60 & 60 \\
\hline 7 & 7017 & Dewi Azizah Susanti & $\mathrm{P}$ & 70 & 75 & 75 & 73 \\
\hline 8 & 7027 & Dimas Atris Stiawan & $\mathrm{L}$ & 60 & 60 & 60 & 60 \\
\hline 9 & 7044 & Dimas Saputra & $\mathrm{L}$ & 75 & 80 & 75 & 77 \\
\hline 10 & 7048 & Dwi Alisya Rahmawati & $\mathrm{P}$ & 65 & 65 & 65 & 65 \\
\hline 11 & 7060 & Elsyana Putri Nugraeni & $\mathrm{P}$ & 60 & 60 & 60 & 60 \\
\hline 12 & 7077 & Frenky Ghana Prima Yoga & $\mathrm{L}$ & 75 & 75 & 75 & 75 \\
\hline 13 & 7082 & Hafisa Olyvia & $\mathrm{P}$ & 75 & 75 & 76 & 75 \\
\hline 14 & 7091 & Handoko & $\mathrm{L}$ & 60 & 60 & 60 & 60 \\
\hline 15 & 7328 & Ikramullah Fauzi & $\mathrm{L}$ & 65 & 65 & 65 & 65 \\
\hline 16 & 7126 & Ilham Dwijokangko & $\mathrm{L}$ & 75 & 75 & 75 & 75 \\
\hline 17 & 7140 & Irfan Zaqqi Maulana & $\mathrm{L}$ & 80 & 75 & 80 & 78 \\
\hline 18 & 7151 & Irman Hidayanti & $\mathrm{L}$ & 75 & 75 & 75 & 75 \\
\hline 19 & 7157 & Ivan Ariffa'i & $\mathrm{L}$ & 60 & 60 & 60 & 60 \\
\hline 20 & 7161 & Mohammad Ainunnauval & $\mathrm{L}$ & 60 & 60 & 60 & 60 \\
\hline 21 & 7180 & $\begin{array}{l}\text { Muhammad Altaf Faadhil } \\
\text { Rahman }\end{array}$ & $\mathrm{L}$ & 70 & 75 & 75 & 73 \\
\hline 22 & 7196 & Muhammad Ipnu Zhahri & $\mathrm{L}$ & 70 & 70 & 70 & 70 \\
\hline 23 & 7210 & Muhammad Jalu Ardiansyah & $\mathrm{L}$ & 70 & 70 & 70 & 70 \\
\hline 24 & 7256 & Nur Wulan Safitri & $\mathrm{P}$ & 80 & 80 & 75 & 78 \\
\hline 25 & 7259 & Safarudin & $\mathrm{L}$ & 70 & 70 & 70 & 70 \\
\hline 26 & 7266 & Satria Rahmananda & $\mathrm{P}$ & 60 & 60 & 65 & 62 \\
\hline 27 & 7278 & Suci Wulan Rahma Dina & $\mathrm{P}$ & 80 & 80 & 75 & 78 \\
\hline 28 & 7280 & Yomah Septi Romandani & $\mathrm{P}$ & 70 & 70 & 70 & 70 \\
\hline 29 & 7285 & Zahra Amelia Putri & $\mathrm{P}$ & 75 & 75 & 75 & 75 \\
\hline
\end{tabular}

\section{Siklus I}

1. Perencanaan Tindakan

Ada beberapa perencanaan tindakan pertama yaitu :

a. Memilih anak yang akan ikut dalam latihan tehnik Passing dalam permainan sepak bola.

b. Mempersiapkan perangkat belajar mengajar, seperti : bola, gawang, dan lainlain.

c. Melakukan pre - tes dengan tehnik passing.

2. Pelaksanaan Tindakan I

Dalam kurikulum, sementara kurikulum sendiri tidak terdapat pokok bahasan permainan sepak bola. Di samping itu juga kurang mengaktifkan program ekstrakulikuler untuk memberikan pedalaman materi yang perlu diajarkan di jam luar sekolah, khususnya pada permainan sepak bola yang sangat memerlukan waktu latihan yang cukup lama. Selain itu juga lingkungan tempat anak pun sering diadakan permainan sepak bola pada sore hari, akan tetapi sayangnya jarang sekali melibatkan anak. 
Dengan menggunakan metode wawancara, penulis mengadakan tanya jawab kepada orang tua / wali murid mengapa anaknya tidak diikutkan pada program ekstrakulikuler, orang tua menjawab, kemauan anak itu sendiri yang kurang tertarik pada permainan sepak bola karena memang butuh waktu lama untuk menguasainya.

3. Faktor yang menghambat penguasaan tehnik Passing dalam permainan sepak bola anak kelas IX G MTs Negeri Batang ada beberapa faktor, yaitu :

- Faktor kekuatan

Di sini masih banyak yang belum mampu menguasai tehnik dasar pasing dalam permainan sepak bola dikarenakan belum begitu menguasai tehnik dan gerak dasar pasing dalam permainan sepak bola.

- Faktor Tehnik

Dilihat dari segi tehnik Passing dalam permainan sepak bola anak masih banyak melakukan kesalahan :

1. Sikap permulaan

- Kaki masih dalam keadaan lurus dan sejajar jarak antara kedua kaki masih terlalu lebar.

- Sikap badan belum terlalu condong ke depan, pada tahap ini akan menyebabkan kurangnya keleluasaan untuk bergerak pada saat menerima bola.

2. Sikap perkenaan

Di sini anak terlalu sering melakukan kesalahan yang cukup merugikan dan fatal :

- Anak masih merasa takut menerima bola sehingga keseimbangan hilang.

- Ayunan kaki masih kaku, sehingga tubuh anak ikut bergerak tidak teratur.

- Di sini anak belum percaya diri untuk melakukan pasing bola, sehingga anak menerima bola dan berusaha mengembalikan dengan sekuat kuatnya sehingga bola tidak terarah baik.

3. Sikap akhir

Sikap akhir ini anak masih menunggu di tempat dan terpaku pandangannya ke arah bola, karena kurang percaya diri dan masih takut menerima bola.

Sehubungan dengan kesalahan - kesalahan di atas pada saat perkenaan dengan bola terlalu kaku atau takut sehingga menghasilkan bola terlalu melambung tinggi dan tidak terarah.

\section{Refleksi Tindakan I}

Berdasarkan hasil observasi pada tindakan pertama anak masih lamban menerima penjelasan guru tentang pasing dalam permainan sepak bola yang benar. Dalam mengatasi masalah ini MTs Negeri Batang khususnya di kelas IX G yaitu dengan cara guru sebaiknya menerapkan perpaduan sikap tehnik pasing dalam permainan sepak bola yang sebenarnya kepada anak dan menjelaskan fungsi sikap tersebut, supaya anak lebih memahami dan dapat melakukan tehnik pasing dalam permainan sepak bola dengan baik dan benar.

Selain itu guru juga dapat melakukan penambahan jam pelajaran atau ekstrakulikuler yang sebaiknya minimal 2 kali seminggu. Di sini maksudnya agar anak lebih banyak mencoba dan dapat melihat masalah tersebut agar anak terbiasa menggunakan pasing dalam permainan sepak bola yang akhirnya dapat bermain sepak bola yang baik dan benar sesuai dengan tehnik - tehnik permainan.

Tabel 5. Tabel siklus 1

\begin{tabular}{|l|l|l|l|}
\hline No & Indikator & Jumlah & Keterangan \\
\hline
\end{tabular}




\begin{tabular}{|c|l|c|c|}
\hline 1 & Jumlah Anak & 29 & \\
\hline 2 & KKM & 75 & \\
\hline 3 & Indikator Keberhasilan & $56,5 \%$ & \\
\hline 4 & Jumlah Anak Tuntas & 15 & \\
\hline 5 & Jumlah Anak Tidak Tuntas & 14 & \\
\hline 6 & Jumlah Nilai & 2066 & \\
\hline 7 & Nilai Rata-rata Kelas & 71,24 & \\
\hline 8 & Presentase Daya Serap & $56,5 \%$ & \\
\hline
\end{tabular}

Tabel 6. Tabel penilaian siklus 1

\begin{tabular}{|c|c|c|c|c|c|c|c|}
\hline \multirow{2}{*}{ NO } & \multirow{2}{*}{$\begin{array}{l}\text { NOMOR } \\
\text { INDUK }\end{array}$} & \multirow{2}{*}{ NAMA } & \multirow{2}{*}{$\begin{array}{c}\mathbf{L} / \\
\mathbf{P}\end{array}$} & \multicolumn{3}{|c|}{ NILAI } & \multirow{2}{*}{$\begin{array}{c}\text { RATA } \\
- \\
\text { RATA }\end{array}$} \\
\hline & & & & $\mathbf{I}$ & II & III & \\
\hline 1 & 6987 & Ahmad Nurwahid & $\mathrm{L}$ & 60 & 60 & 60 & 60 \\
\hline 2 & 6991 & Aidik Hadist Nur Syaputra & $\mathrm{L}$ & 70 & 70 & 70 & 70 \\
\hline 3 & 6990 & Alifatuddiniyah & $P$ & 70 & 70 & 70 & 70 \\
\hline 4 & 7003 & Ana Ismatul Hawa & $P$ & 60 & 60 & 65 & 62 \\
\hline 5 & 7011 & Ani Listiah Wati & $\mathrm{P}$ & 70 & 70 & 70 & 70 \\
\hline 6 & 7013 & Danar Dwi Anugrah & $\mathrm{L}$ & 60 & 60 & 60 & 60 \\
\hline 7 & 7017 & Dewi Azizah Susanti & $P$ & 75 & 75 & 75 & 75 \\
\hline 8 & 7027 & Dimas Atris Stiawan & $\bar{L}$ & 75 & 75 & 75 & 75 \\
\hline 9 & 7044 & Dimas Saputra & $\mathrm{L}$ & 65 & 65 & 65 & 65 \\
\hline 10 & 7048 & Dwi Alisya Rahmawati & $\mathrm{P}$ & 75 & 75 & 75 & 75 \\
\hline 11 & 7060 & Elsyana Putri Nugraeni & $P$ & 60 & 60 & 60 & 60 \\
\hline 12 & 7077 & Frenky Ghana Prima Yoga & $\mathrm{L}$ & 75 & 75 & 75 & 75 \\
\hline 13 & 7082 & Hafisa Olyvia & $\mathrm{P}$ & 75 & 75 & 75 & 75 \\
\hline 14 & 7091 & Handoko & $\mathrm{L}$ & 78 & 78 & 78 & 78 \\
\hline 15 & 7328 & Ikramullah Fauzi & $\mathrm{L}$ & 65 & 65 & 65 & 65 \\
\hline 16 & 7126 & Ilham Dwijokangko & $\mathrm{L}$ & 75 & 75 & 75 & 75 \\
\hline 17 & 7140 & Irfan Zaqqi Maulana & $\mathrm{L}$ & 80 & 75 & 80 & 78 \\
\hline 18 & 7151 & Irman Hidayanti & $\overline{\mathrm{L}}$ & 75 & 75 & 75 & 75 \\
\hline 19 & 7157 & Ivan Ariffa'i & $\mathrm{L}$ & 80 & 75 & 78 & 78 \\
\hline 20 & 7161 & Mohammad Ainunnauval & $\mathrm{L}$ & 60 & 60 & 60 & 60 \\
\hline 21 & 7180 & $\begin{array}{l}\text { Muhammad Altaf Faadhil } \\
\text { Rahman }\end{array}$ & $\mathrm{L}$ & 75 & 75 & 75 & 75 \\
\hline 22 & 7196 & Muhammad Ipnu Zhahri & $\mathrm{L}$ & 78 & 78 & 78 & 78 \\
\hline 23 & 7210 & Muhammad Jalu Ardiansyah & $\mathrm{L}$ & 70 & 70 & 70 & 70 \\
\hline 24 & 7256 & Nur Wulan Safitri & $\mathrm{P}$ & 80 & 80 & 75 & 78 \\
\hline 25 & 7259 & Safarudin & $\mathrm{L}$ & 76 & 78 & 78 & 77 \\
\hline 26 & 7266 & Satria Rahmananda & $\mathrm{P}$ & 60 & 60 & 65 & 62 \\
\hline 27 & 7278 & Suci Wulan Rahma Dina & $P$ & 70 & 70 & 70 & 70 \\
\hline 28 & 7280 & Yomah Septi Romandani & $\mathrm{P}$ & 70 & 70 & 70 & 70 \\
\hline 29 & 7285 & Zahra Amelia Putri & $\mathrm{P}$ & 75 & 75 & 75 & 75 \\
\hline
\end{tabular}




\section{Siklus II}

1. Perencanaan Tindakan II antara lain :

Ada beberapa yang harus dipersiapkan oleh peneliti pada tahap ini,

a. Mempersiapkan perangkat kegiatan beajar mengajar.

b. Mengadakan apresiasi dengan memotivasi anak.

c. Menjelaskan tehnik pasing dalam permainan sepak bola yang benar.

d. Memberi kesempatan kepada anak untuk bertanya menuangkan idenya.

e. Melakukan praktek dengan membimbing anak secara individual.

f. Mengadakan evaluasi.

2. Tahap Tindakan II

a. Waktu pelaksanaan : waktu pelaksanaan tindakan tahap kedua ini dilakukan pada tanggal 03 Januari 2022

b. Tempat pelaksanaan : MTs Negeri Batang

c. Kegiatan belajar mengajar :

- Memberikan motivasi kepada anak agar semangat di dalam latihan.

- Memberikan kepada anak untuk praktek sendiri.

- Guru menjelaskan kembali tehnik pasing dalam permainan sepak bola yang baik dan benar.

- Guru membimbing anak dalam mempraktikkan tehnik pasing dalam permainan sepak bola

- Kegiatan ini dilakukan selama 90 menit.

3. Observasi Tindakan II

Dari hasil pengamatan peneliti pada siklus kedua ini ketrampilan pasing yang dimiliki anak sudah meningkat dibandingkan dengan Siklus I. Dan di dalam melakukan latihan anak sudah menunjukkan keseriusan dan semangat dalam permainan sepak bola.

4. Refleksi Tindakan II

Berdasarkan hasil observasi pada tindakan kedua ini anak sudah menunjukkan ketrampilannya dalam melakukan pasing dalam permainan sepak bola. Untuk proses belajar mengajar selanjutnya perlu lebih meningkatkan kembali tehnik permainan sepak bola secara keseluruhan agar anak dapat bermain sepak bola dengan benar.

Tabel 7. Tabel penilaian

\begin{tabular}{|l|l|c|c|}
\hline No & Indikator & Jumlah & Keterangan \\
\hline 1 & Jumlah Anak & 29 & \\
\hline 2 & KKM & 75 & \\
\hline 3 & Indikator Keberhasilan & $83 \%$ & \\
\hline 4 & Jumlah Anak Tuntas & 24 & \\
\hline 5 & Jumlah Anak Tidak Tuntas & 5 & \\
\hline 6 & Jumlah Nilai & 2173 & \\
\hline 7 & Nilai Rata-rata Kelas & 74,93 & \\
\hline 8 & Presentase Daya Serap & $83 \%$ \\
\hline
\end{tabular}


Tabel 8. Tabel penilaian siklus 2

\begin{tabular}{|c|c|c|c|c|c|c|c|}
\hline \multirow{2}{*}{ NO } & \multirow{2}{*}{$\begin{array}{c}\text { NOMOR } \\
\text { INDUK }\end{array}$} & \multirow{2}{*}{ NAMA } & \multirow{2}{*}{$\begin{array}{c}\mathbf{L} / \\
\mathbf{P}\end{array}$} & \multicolumn{3}{|c|}{ NILAI } & \multirow{2}{*}{$\begin{array}{c}\text { RATA } \\
\text { - } \\
\text { RATA }\end{array}$} \\
\hline & & & & $\mathbf{I}$ & II & III & \\
\hline 1 & 6987 & Ahmad Nurwahid & $\mathrm{L}$ & 78 & 78 & 78 & 78 \\
\hline 2 & 6991 & Aidik Hadist Nur Syaputra & $\mathrm{L}$ & 75 & 78 & 78 & 77 \\
\hline 3 & 6990 & Alifatuddiniyah & $\mathrm{P}$ & 70 & 70 & 70 & 70 \\
\hline 4 & 7003 & Ana Ismatul Hawa & $\mathrm{P}$ & 78 & 78 & 78 & 78 \\
\hline 5 & 7011 & Ani Listiah Wati & $\mathrm{P}$ & 70 & 70 & 70 & 70 \\
\hline 6 & 7013 & Danar Dwi Anugrah & $\mathrm{L}$ & 78 & 75 & 78 & 77 \\
\hline 7 & 7017 & Dewi Azizah Susanti & $\mathrm{P}$ & 75 & 75 & 75 & 75 \\
\hline 8 & 7027 & Dimas Atris Stiawan & $\mathrm{L}$ & 75 & 75 & 75 & 75 \\
\hline 9 & 7044 & Dimas Saputra & $\mathrm{L}$ & 78 & 80 & 80 & 79 \\
\hline 10 & 7048 & Dwi Alisya Rahmawati & $\mathrm{P}$ & 75 & 75 & 75 & 75 \\
\hline 11 & 7060 & Elsyana Putri Nugraeni & $\mathrm{P}$ & 60 & 60 & 60 & 60 \\
\hline 12 & 7077 & Frenky Ghana Prima Yoga & $\mathrm{L}$ & 75 & 75 & 75 & 75 \\
\hline 13 & 7082 & Hafisa Olyvia & $\mathrm{P}$ & 75 & 75 & 75 & 75 \\
\hline 14 & 7091 & Handoko & $\mathrm{L}$ & 78 & 78 & 78 & 78 \\
\hline 15 & 7328 & Ikramullah Fauzi & $\mathrm{L}$ & 75 & 75 & 75 & 75 \\
\hline 16 & 7126 & Ilham Dwijokangko & $\mathrm{L}$ & 75 & 75 & 75 & 75 \\
\hline 17 & 7140 & Irfan Zaqqi Maulana & $\bar{L}$ & 80 & 75 & 80 & 78 \\
\hline 18 & 7151 & Irman Hidayanti & $\mathrm{L}$ & 75 & 75 & 75 & 75 \\
\hline 19 & 7157 & Ivan Ariffa'i & $\mathrm{L}$ & 80 & 75 & 78 & 78 \\
\hline 20 & 7161 & Mohammad Ainunnauval & $\mathrm{L}$ & 60 & 60 & 60 & 60 \\
\hline 21 & 7180 & $\begin{array}{l}\text { Muhammad Altaf Faadhil } \\
\text { Rahman }\end{array}$ & $\mathrm{L}$ & 70 & 70 & 75 & 72 \\
\hline 22 & 7196 & Muhammad Ipnu Zhahri & $\mathrm{L}$ & 78 & 78 & 78 & 78 \\
\hline 23 & 7210 & Muhammad Jalu Ardiansyah & $\mathrm{L}$ & 78 & 78 & 75 & 77 \\
\hline 24 & 7256 & Nur Wulan Safitri & $\mathrm{P}$ & 80 & 80 & 75 & 78 \\
\hline 25 & 7259 & Safarudin & $\mathrm{L}$ & 76 & 78 & 78 & 77 \\
\hline 26 & 7266 & Satria Rahmananda & $\mathrm{P}$ & 78 & 78 & 78 & 78 \\
\hline 27 & 7278 & Suci Wulan Rahma Dina & $\mathrm{P}$ & 75 & 75 & 75 & 75 \\
\hline 28 & 7280 & Yomah Septi Romandani & $\mathrm{P}$ & 78 & 78 & 78 & 78 \\
\hline 29 & 7285 & Zahra Amelia Putri & $\mathrm{P}$ & 78 & 78 & 75 & 77 \\
\hline
\end{tabular}

\section{Pembahasan}

Hasil penelitian menunjukkan bahwa proses latihan yang kondusif dapat meningkatkan keterampilan bermain sepak bola dan dapat menggunakan tehnik pasing dengan benar. Keterampilan anak meningkat karena anak lebih aktif belajar dan tumbuhnya rasa percaya diri serta semangat di dalam kelompok bermainnya. Yang lebih tampak kekompakan dan kerja sama untuk memahami tehnik pasing ini dengan memecahkan kesulitan secara bersama. 
Subjek penelitian ini adalah anak kelas IX G MTs Negeri Batang, maka anak harus berprakarsa sendiri, mengamati, menganalisa, membantu penilaian dan sebagainya. Fungsi guru hanya sebagai fasilitator atau pembimbing sesuai dengan prinsip belajar dengan keaktifan dalam belajar dan mengikuti latihan.

Hasil penelitian ini membuktikan bahwa bimbingan guru sebagai pendidikan sangat membantu menumbuhkan semangat dan motivasi kepada anak untuk lebih meningkatkan ketrampilan tehnik passing dalam permainan sepak bola.

Sungguh pun demikian guru harus meyakinkan anak bahwa belajar dan latihan secara efektif dan serius dapat berpengaruh pada keberhasilan anak untuk meningkatkan ketrampilan bermain sepak bola dan hal ini juga tergantung kepada sejauh mana anak dapat memanfaatkan waktu yang diberikan dan keseriusan anak dalam mengikuti latihan baik dalam waktu pelajaran penjasorkes maupun waktu diberikan ekstrakulikuler.

Selanjutnya dilihat dari kompetensi 29 anak terjadi peningkatan dari prasiklus,siklus 1 dan siklus 2 :

1. Prasiklus anak yang tuntas 10 siswa dengan indikator keberhasilan $34 \%$

2. Siklus 1 anak yang tuntas 15 siswa dengan indikator keberhasilan $56,5 \%$

3. Siklus 2 anak yang tuntas 24 siswa dengan indikator keberhasilan $83 \%$

Dari hasil penelitian ini terjadi peningkatan setiap siklusnya.

Maka terjadi peningkatan hasil belajar teknik dasar sepak bola dengan pendekatan bermain anak kelas IX MTs Negeri Batang.

\section{KESIMPULAN}

Dalam melakukan Penelitian Tindakan Kelas di MTs Negeri Batang tentang "Peningkatan hasil belajat teknik dasar sepak bola dengan pendekatan bermain anak kelas IX G MTs Negeri Batang tahun 2022 " dapat disimpulkan beberapa hal :

1. Faktor - faktor yang menghambat kemampuan tehnik dasar sepak bola di kelas IX G diantaranya :

a. Faktor kekuatan, anak belum mampu melakukan pasingan bola dalam permainan sepak bola.

b. Faktor tehnik, anak belum mampu memahami dan menerapkan rangkaian gerakan tehnik dasar sepak bola dengan baik.

2. Cara mengatasi tehnik dasar sepak bola salah satu yaitu memberikan latihan yang khusus di luar jam sekolah tentang penerapan gerakan tehnik dasar sepak bola agar lebih banyak mencoba dan bisa memecahkan masalah sendiri dengan bimbingan guru.

\section{DAFTAR PUSTAKA}

Arikunto S. 2006. Prosedur Penelitian Suatu Pendekatan Praktik, Jakarta : Rineka Cipta

Arikunto, Suharsimi. 2005. Penelitian Tindakan Kelas, Jakarta : Dirjen PMPPTK

Arsyad, A. 2002. Media Pembelajaran, edisi 1. Jakarta : PT. Raja Grafindo Persada

Chandra, Sodikin. 2010. Pendidikan Jasmani Olahraga dan Kesehatan, Jakarta :Pusat Perbukuan Kemendiknas.

Clive G. 2003. Sepak Bola. Jakarta : Airlangga

Faruq M. 2008. Meningkatkan Kebugaran Tubuh melalui Permainan Dan Olahraga Sepakbola. Surabaya : Grasindo

Jef S. 1988. Sepakbola Dan Strategi Bermain. Bandung : Remaja Karya

Kosasih E. 1994. Olahraga Pilihan. Jakarta : Depdiknas

Lutan R., dkk. 2000. Penelitian Penjaskes. Jakarta : Depdikbud

Luxbacer J., 2011. Sepak Bola Edisi Kedua. Jakarta : Rajagrafindo

Mielke D. 2007. Dasar-Dasar Sepak Bola. Bandung : Pakar Raya Pustaka

Sugiyono. 2010. Metode Penelitian Pendidikan, Bandung : Alfabeta

Suharsono, Et.al. 2005. Pedoman Penyusunan Karya Tulis Ilmiah di Bidang Pendidikan dan Angka Kredit Pengembangan Profesi Guru. Jakarta : Dirjen Dikgu dan Tentis. 
Wasis D Dwiyogo. 2008. Penelitian dan Pengembangan Olahraga. Malang : Lemlit UNM Wibawa, Basuki. 2003. Penelitian Tindakan Kelas. Jakarta : Depdiknas Dirjen Dirtendik. 